\title{
Implications of Decompressive Surgical Procedures for Lumbar Spine Stenosis on the Biomechanics of the Adjacent Segment: A Finite Element Analysis
}

\author{
Francesco Travascio ${ }^{1}$, Shihab Asfour ${ }^{1 *}$, Joseph Gjolaj ${ }^{2}$, Loren L. Latta ${ }^{2}$, Shady Elmasry ${ }^{1}$ and Frank Eismont ${ }^{2}$ \\ ${ }^{1}$ Biomechanics Research Lab, Department of Industrial Engineering, University of Miami, Coral Gables, USA \\ ${ }^{2}$ Department of Orthopaedics, Miller School of Medicine, University of Miami, Miami, FL, USA
}

\begin{abstract}
Surgeries for Lumbar Spinal Stenosis (LSS) aim at decompressing spinal nerves and relieving symptoms of radiculopathy or myelopathy. Frequently after surgery, stenosis may progress in adjacent spinal segments, but the etiology of adjacent segment degeneration is still unclear. It is hypothesized that surgical approaches for LSS may alter the normal biomechanics of adjacent segments, eventually contributing to the development of stenosis. This study investigated implications of established decompressive surgical approaches on adjacent segments biomechanics.
\end{abstract}

A realistic finite element model of a L1-L5 human lumbar spine was used for assessing changes in spine segments' biomechanics due to laminotomy and laminectomy surgeries. First, the model was validated by comparing its predictions to previously reported spine kinematic data obtained after multi-level laminotomy and laminectomy. Subsequently, using a hybrid loading protocol, segments' kinematics, intradiscal pressure, and stress in flexionextension were investigated simulating single level (L4-L5) laminotomy and laminectomy procedures.

Alterations of spine segments biomechanics due to laminotomy were minimal. In contrast, after laminectomy, the L3-L4 range of motion, intradiscal pressure, and stress increased up to $50 \%, 20 \%$, and $120 \%$, respectively. These results suggest that laminotomy represents a better approach than laminectomy for reducing risks of spine instability or mechanically-accelerated disc degeneration in adjacent segments.

Keywords: Lumbar stenosis; Laminotomy; Laminectomy; Adjacent segment degeneration; Finite element analysis

\section{Introduction}

With a prevalence of approximately $20 \%$ in individuals older than 60 years, and up to $80 \%$ in those older than 70 years, Lumbar Spinal Stenosis (LSS) is exerting a greater clinical impact as the population ages $[1,2]$. The clinical presentation of LSS, defined as radiculopathy or myelopathy, is characterized by lower extremity pain, paresthesias and weakness and may also contribute to low back pain [3-5].

The pathogenesis of LSS is attributable to bone remodeling or overgrowth, intervertebral disc (IVD) protrusion, spondylolisthesis, or any combination of these [3]. Bone overgrowth is either initiated or accelerated by the degenerative process affecting facet joints and IVD [6]. Remodeling of the bone is either a reaction to the excessive joint motion or a physiologic attempt for local arthrodesis, eventually resulting in decreased segmental mobility. This loss of mobility in one segment creates abnormal forces and stresses on adjacent spinal segments, which then degenerate at an accelerated rate [3].

The LSS is often surgically treated. The objective of surgery is decompression of the spinal nerves without causing spinal instability [7]. In the past 60 years, a myriad of surgical techniques have been developed for achieving spinal nerve decompression. Among them, lumbar laminectomy with or without fusion are well-established approaches [8]. However, longitudinal studies on surgically treated patients report the occurrence of adjacent segment degeneration (e.g., disc herniation, spondylolisthesis, newly developed stenosis, etc., at adjacent spinal segments) after fusion or laminectomy [9-14]. Consequently, a large proportion of those patients require additional procedures to address the adjacent segment degeneration (ASD), especially if they experience symptoms of recurrent stenosis related to the ASD, which has been clinically defined as adjacent segment disease $[11,13,15-17]$. All surgical treatments for LSS involve alteration of the bony and soft tissue anatomy in the affected portion of the spine. The particular alterations to the musculoskeletal anatomy generated by each of these procedures may alter the normal physiological biomechanics of untreated segments of the spine $[18,19]$. Such alterations might have implications for the development of the adjacent segment disease.

Laminectomy or laminotomy are the preferred surgical approaches when there are no indications of pre-operative spinal instability [2022]. The implications of such surgical approaches on the biomechanical behavior of the spine have been investigated via clinical [20-27] in vitro, [19,28-33] and numerical studies [34-40]. However, information on the specific alterations of adjacent spinal segment biomechanics due to these surgical procedures is still incomplete. Hence, the objective of this study was to provide new insights on the implications of laminectomy and laminotomy on the mechanical behavior of adjacent spinal segments.

\section{Methods}

A realistic computational model was developed to describe the biomechanical behavior of lumbar spine undergoing common surgical procedures such as unilateral laminotomy, bilateral laminotomy, and facet-sparing laminectomy. An additional procedure that is not typically performed clinically, laminectomy with complete facetectomy, was included for biomechanical comparison purposes. First, the model was

*Corresponding author: Shihab Asfour, Department of Industrial Engineering, College of Engineering, University of Miami, Coral Gables, FL 33124-0621, USA Tel: (305) 284-2367; Fax: (305) 284-4040; E-mail: sasfour@miami.edu

Received February 12, 2015; Accepted March 17, 2015; Published March 19 2015

Citation: Travascio F, Asfour S, Gjolaj J, Latta LL, Elmasry S, Eismont F (2015) Implications of Decompressive Surgical Procedures for Lumbar Spine Stenosis on the Biomechanics of the Adjacent Segment: A Finite Element Analysis. J Spine 4 220. doi: $10.4172 / 21657939.1000220$

Copyright: (c) 2015 Travascio F, et al. This is an open-access article distributed under the terms of the Creative Commons Attribution License, which permits unrestricted use, distribution, and reproduction in any medium, provided the original author and source are credited. 
validated by comparing its predictions of spinal segments motion to experimental data reported in an in vitro study [28]. Subsequently, the model was utilized for assessing and comparing post-operative changes of adjacent segment biomechanics in terms of segment kinematics (range of motion), intradiscal fluid pressure, and stress fields in IVD. Details on methods and procedures are reported below.

\section{Lumbar spine computational model}

A three-dimensional nonlinear finite element model of the lumbar spine was developed. It consisted of the L1 to L5 vertebrae, associated IVDs, intact facet joints, and all major ligaments of lumbar spine. The geometry of the computational domain was obtained from a CT of a normal, non-pathological spine. Vertebrae were modeled as rigid bodies. The IVDs were constituted by two distinct anatomic regions: the annulus fibrosus (AF) and the nucleus pulposus (NP). Both AF and NP were considered as biphasic media [41,42] constituted by a solid phase embedded in a fluid phase. More specifically, the solid phase of AF was modeled as a fiber reinforced hyperelastic composite: collagen fibers were modeled as tension-only elements [43] and arranged in a total of four concentric layers enclosing the NP with alternating $\pm 30^{\circ}$ orientation [44] the ground substance of AF was modeled as a MooneyRivlin material [45]. The solid phase of NP was isotropic elastic, with mechanical properties taken from a previous study [46]. Water volumetric fractions and hydraulic permeability for both NP and AF were those reported in the literature [47-49]. Each facet joint had a gap of $0.5 \mathrm{~mm} 44$ and two cartilaginous layers which were modeled as elastic isotropic materials [50]. The ligaments were represented by linear elastic tension-only spring elements, and their stiffness was that reported by Pintar and co-workers [51]. A summary of the material properties used in this model is reported in Table 1.

Both IVD and cartilaginous layers at facet joints were modeled with 8-node hexahedral elements ( 23200 elements for each IVD, and $\sim 1000$ element for each cartilage layer). Non-commercial software FEBio (FEBio 1.8.0, Musculoskeletal Research Laboratory, University of Utah, Salt Lake City, UT) was used to solve the set of governing equations defining the computational model. The FEBio software suite is a nonlinear implicit finite element framework designed specifically for analysis in computational solid biomechanics, whose accuracy and the robustness have been documented [52,53].

\section{Simulated surgical procedures}

Surgical procedures simulated in this study include unilateral laminotomy, bilateral laminotomy, facet-sparing laminectomy, and laminectomy with complete facetectomy. In this study, the ligamentum flavum at each spinal segment was modeled as composed of two spring elements (one element for each operative side). Accordingly, for unilateral laminotomy, only the spring element corresponding to the operative side was removed, together with part of the vertebral lamina. In contrast, for bilateral laminotomy, the entire ligamentum flavum connecting the two vertebral bodies (i.e., both spring elements) was removed. When simulating facet-sparing laminectomy, the entire lamina of the vertebra was removed, together with the connecting flavum, interspinous, and supraspinous ligaments. For the comparison case of laminectomy with complete facetectomy, in addition to all the steps performed in the case of facet-sparing laminectomy, the facet joints (including cartilaginous layers and capsular ligaments) were also removed. The spine models resulting from these procedures are shown in Figure 1.

\section{Model validation}

A preliminary validation was performed by comparing model predictions to experimental data reporting the effects of laminotomy and laminectomy on lumbar spine kinematics. Several experimental characterizations of spine biomechanics after decompressive surgeries for lumbar stenosis have been reported [19,29-32]. Each of these studies uses a different testing protocol, and addresses a specific subset of surgical approaches (e.g., facetectomy and laminectomy, graded facetectomy, bilateral laminotomy and laminectomy, etc.). Hence, quantitative information on spine biomechanics suitable for validating the model adopted in this study is fragmented. To the authors' best knowledge, the in vitro analysis developed in Lee et al. [28] is the only one to report information on spine biomechanics after bilateral laminotomy and laminectomy in human spine, which is the standard for biomechanical evaluation. Accordingly, the experimental conditions used by Lee and co-workers were replicated in the simulations. More specifically, in the investigated cases, the inferior endplate of L5 was fixed (equivalent to potting the lumbar spine at L5), and a pure flexion/ extension moment was applied at the superior endplate of $\mathrm{L} 1(8 \mathrm{Nm}$ in flexion and $6 \mathrm{Nm}$ in extension, respectively) with a frequency of $1 \mathrm{~Hz}$. In addition, a follower load of $400 \mathrm{~N}$ was applied to the spine as previously described [54]. Both laminotomy and laminectomy procedures were performed on L2-L5 segments (Figures $1 \mathrm{~b}$ and 1c). The ranges of motion (rotations in the sagittal plane) of L2-L3, L3-L4, and L4-L5 segments were evaluated and compared to the in vitro results of Lee et al. [28]. In order to improve the agreement with the experiments, the initially chosen elastic moduli of some discs were slightly modified in

\begin{tabular}{|c|c|c|c|}
\hline Material & Property & Value & Reference \\
\hline \multirow{4}{*}{ AF } & Volumetric fluid fraction & 0.75 & {$[47]$} \\
\cline { 2 - 4 } & Hydraulic permeability & $0.00021 \mathrm{~mm}^{4} \mathrm{~N}^{-1} \mathrm{~s}^{-1}$ & {$[48]$} \\
\cline { 2 - 4 } & Collagen fibers (tension-only) & Stress-strain curve & {$[43]$} \\
\cline { 2 - 4 } & $\begin{array}{c}\text { Ground substance Mooney-Rivlin } \\
\text { coefficients }\end{array}$ & c1=0.18; c2=0.045 & {$[45]$} \\
\hline \multirow{3}{*}{ NP } & Volumetric fluid fraction & 0.86 & {$[47]$} \\
\cline { 2 - 4 } & Hydraulic permeability & $0.00067 \mathrm{~mm}^{4} \mathrm{~N}^{-1} \mathrm{~s}^{-1}$ & {$[49]$} \\
\cline { 2 - 4 } & $\begin{array}{c}\text { Ground substance isotropic } \\
\text { elastic modulus }\end{array}$ & $\mathrm{E}=0.2 \mathrm{MPa}$ & {$[46]$} \\
\cline { 2 - 4 } & Ground substance Poisson ratio & $\mathrm{v}=0.499$ & {$[46]$} \\
\hline \multirow{2}{*}{ Cartilage } & Isotropic elastic modulus & $\mathrm{E}=35 \mathrm{MPa}$ & {$[50]$} \\
\cline { 2 - 4 } & Poisson ratio & $\mathrm{v}=0.4$ & {$[50]$} \\
\hline Ligaments & Stiffness (tension-only) & Linear elastic & {$[51]$} \\
\hline
\end{tabular}

Table 1: Material properties of the different tissues used for the finite element model.

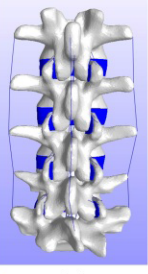

(a)

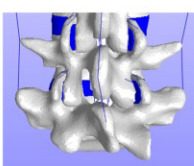

(d)

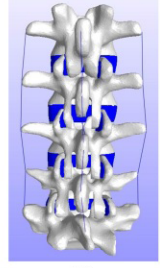

(b)

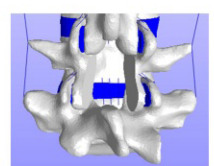

(f)

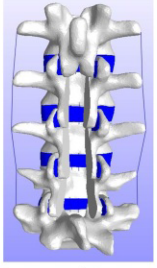

(c)

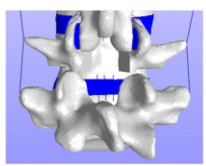

(g)
Figure 1: Posterior view of computational domains used for the simulations: (a) intact spine; (b) bilateral laminotomy at L2-L5; (c) facet-sparing laminectomy at L2-L5; (d) unilateral laminotomy at L4-L5; (e) bilateral laminotomy at L4-L5; (f) facet-sparing laminectomy at L4-L5; (g) laminectomy with facetectomy at L4-L5. 
the computational model within their physiological range. For all the cases investigated, it was found that the predicted range of motion of the model followed the same trend of in vitro data, and their differences were always less than one standard deviation (Figure 2).

\section{Analysis of spine segments biomechanics}

In this analysis, the surgical procedures of unilateral laminotomy, bilateral laminotomy, facet-sparing laminectomy, and laminectomy with complete facetectomy were performed at L4-L5, since this was assumed to be the spine level affected by pathology (Figures $1 \mathrm{~d}-1 \mathrm{~g}$ ). The post-operative changes in range of motion (i.e., rotation in the sagittal plane, anteroposterior translation, and axial translation), intradiscal pressure, and normal and shear stress in both AF and NP were evaluated at all spine levels. A hybrid test method 55 was adopted as a protocol for spine loading conditions. More specifically, the 'intact' spine was tested with the same loading conditions used for validation, and its total range of motion was computed. When testing the spine for each surgical procedure, the pure flexion/extension moment applied at L1 was varied in order to make the total range of motion equal to that attained in the 'intact' case.

\section{Results}

The total range of motion of the spine (L1-L5) in the sagittal plane resulting from loading the intact model was $11.46^{\circ}$ for flexion and $14.3^{\circ}$ for extension. The moments required to produce the same range of motion after performing the surgical procedures are shown in Table 1. Moments changed during flexion, decreasing up to $42 \%$ for the case of laminectomy with facetectomy. Conversely, minimal changes were found during extension for all procedures investigated.

Post-operative alterations of spinal segments biomechanics during extension were minimal $(<5 \%)$ and are not reported. The post-operative motion redistribution during flexion for the individual spine segments is reported in Figure 3, and compared to the 'intact' case. For all procedures, sagittal rotations increased at L4-L5 and L3-
L4, and decreased at L2-L3 and L1-L2. Major changes were found after laminectomies, with increments up to $18 \%$ and $23 \%$ (at L3-L4 and L4-L5, respectively), and reductions up to $15 \%$ and $39 \%$ (at L2L3 and L1-L2, respectively). In contrast, post-operative changes after either unilateral or bilateral laminotomy were minimal $(<5 \%)$, (Figure 3a). Similar trends were observed in the anteroposterior translations: after all the procedures, translations increased at L4-L5 and L3-L4, and decreased at the above segments. The only exception was found at L2L3, where unilateral and bilateral laminotomy caused anteroposterior translation to increase up to $2.52 \mathrm{~mm}(18 \%)$ and $2.46 \mathrm{~mm}$ (15\%), respectively (Figure $3 b$ ). For all the procedures investigated, increments in the axial compression did not exceed $0.2 \mathrm{~mm}$ (Figure 3c).

Post-operative alterations of spinal segments kinematics were reflected in changes of intradiscal pressure and stresses in the IVDs. After laminectomy procedures, intradiscal pressure increased in both NP and AF at L3-L4 (up to 20\%) and L4-L5 (up to 10\%). Conversely, at L2-L3 and L1-L2, pressure reduced up to $35 \%$ and $31 \%$, respectively (Figure 4). After either unilateral or bilateral laminotomy, pressure changes were minor at all spine levels, with the exception of L3-L4, whose fluid pressure in AF dropped up to 30\% (Figure 4b). Changes in the normal stresses were similar to those found in intradiscal pressure: after laminectomy procedures, stress in both NP and AF increased one-fold in L4-L5 and L3-L4, and decreased up to 30\% to 35\% in L2L3 and L1-L2, respectively, (Figure 5a and 5b). Again, after unilateral and bilateral laminotomy, no major changes from the 'intact' case were observed for all the spine levels. Major changes in shear stress were only observed in the NP of L3-L4 after laminectomy procedures, increasing up to $120 \%$ the value attained in the 'intact' case (Figure $5 \mathrm{c}$ and $5 \mathrm{~d}$ ).

\section{Discussion}

In this study, we adopted a realistic three-dimensional finite element model of human lumbar spine to investigate the implications of surgical procedures for lumbar stenosis on the biomechanics of the adjacent segments. Specifically, the model was implemented to simulate

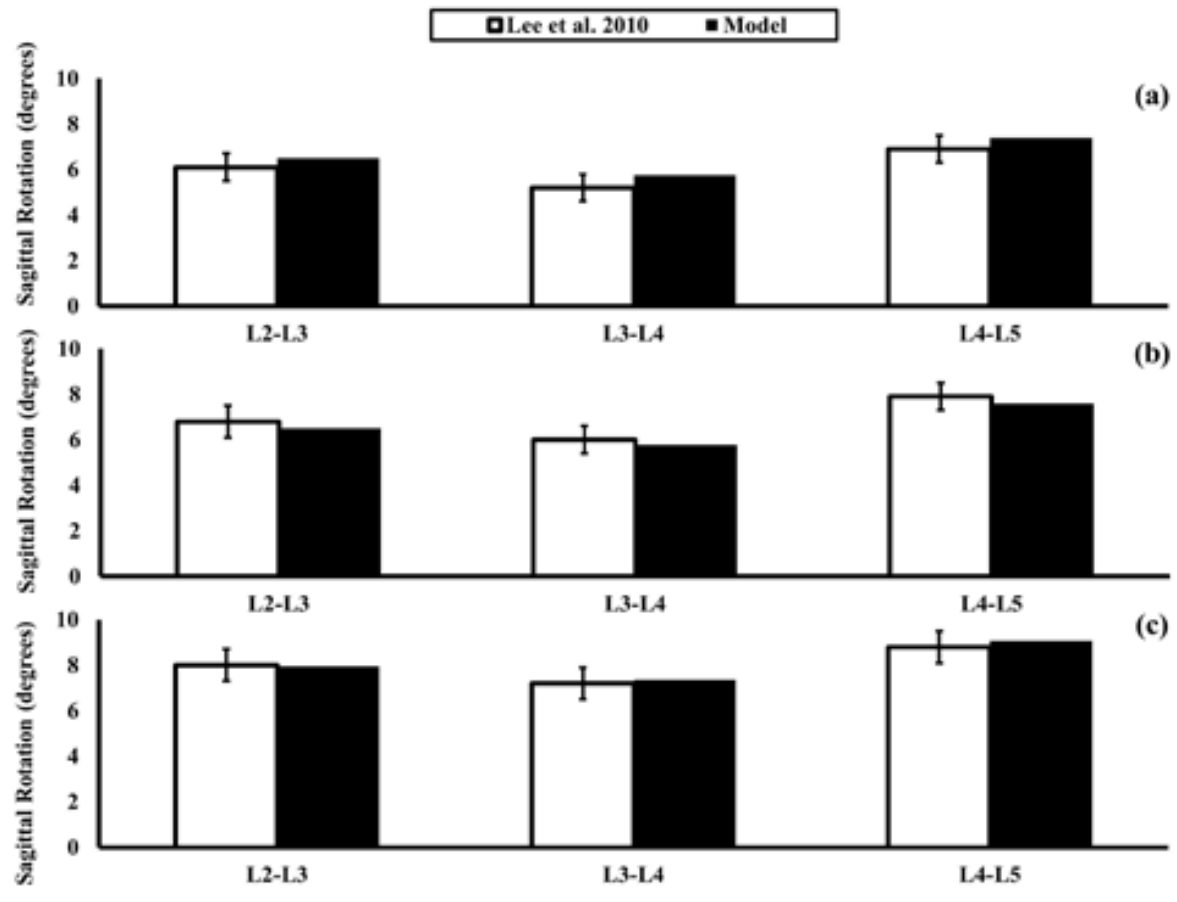

Figure 2: Validation of the computational model of the spine: the rotations in the sagittal plane of vertebral segments predicted by the model are compared to those reported the in vitro results by Lee et al. [28]: (a) intact spine; (b) bilateral laminotomy at L2-L5; (c) laminectomy at L2-L5. 
Citation: Travascio F, Asfour S, Gjolaj J, Latta LL, Elmasry S, Eismont F (2015) Implications of Decompressive Surgical Procedures for Lumbar Spine Stenosis on the Biomechanics of the Adjacent Segment: A Finite Element Analysis. J Spine 4: 220. doi:10.4172/21657939.1000220

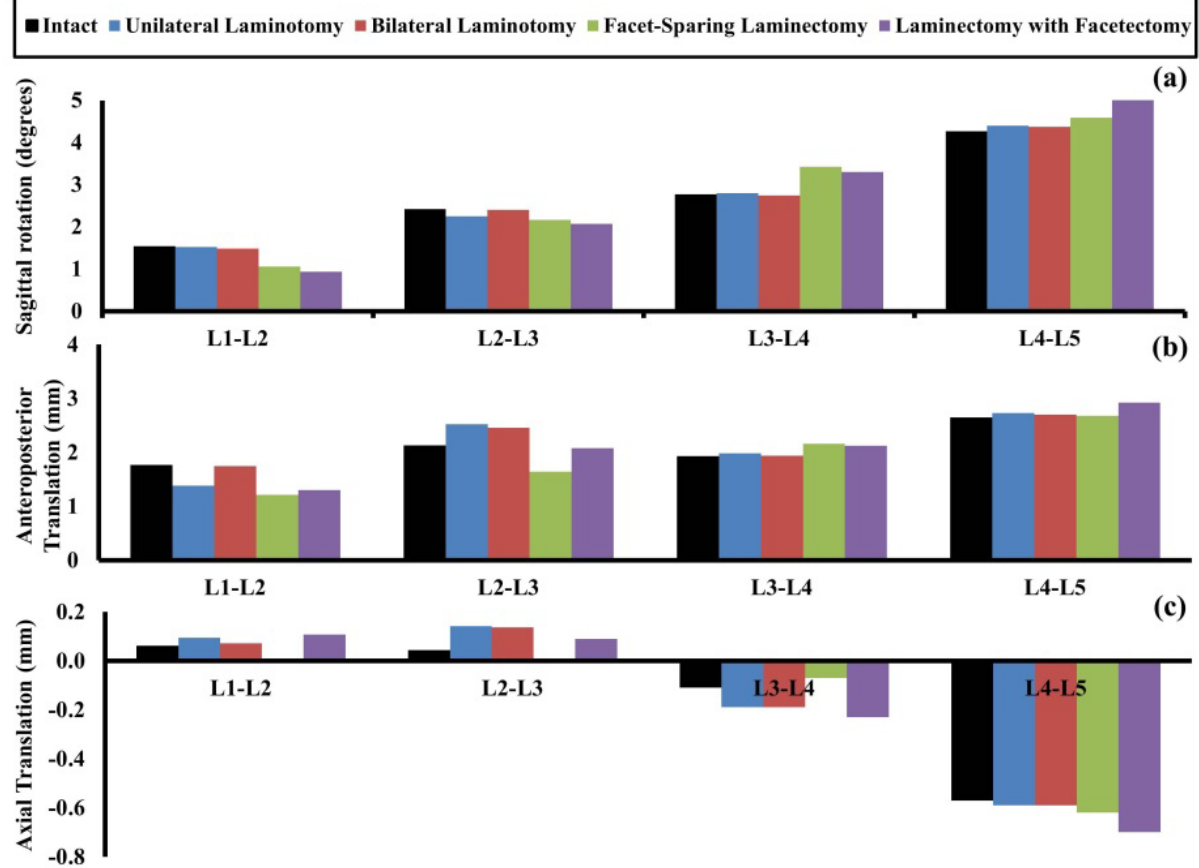

Figure 3: Post-operative changes in range of motion of spine segments: (a) rotation in the sagittal plane; (b) anteroposterior translation; (c) axial translation (negative sign indicates compression).

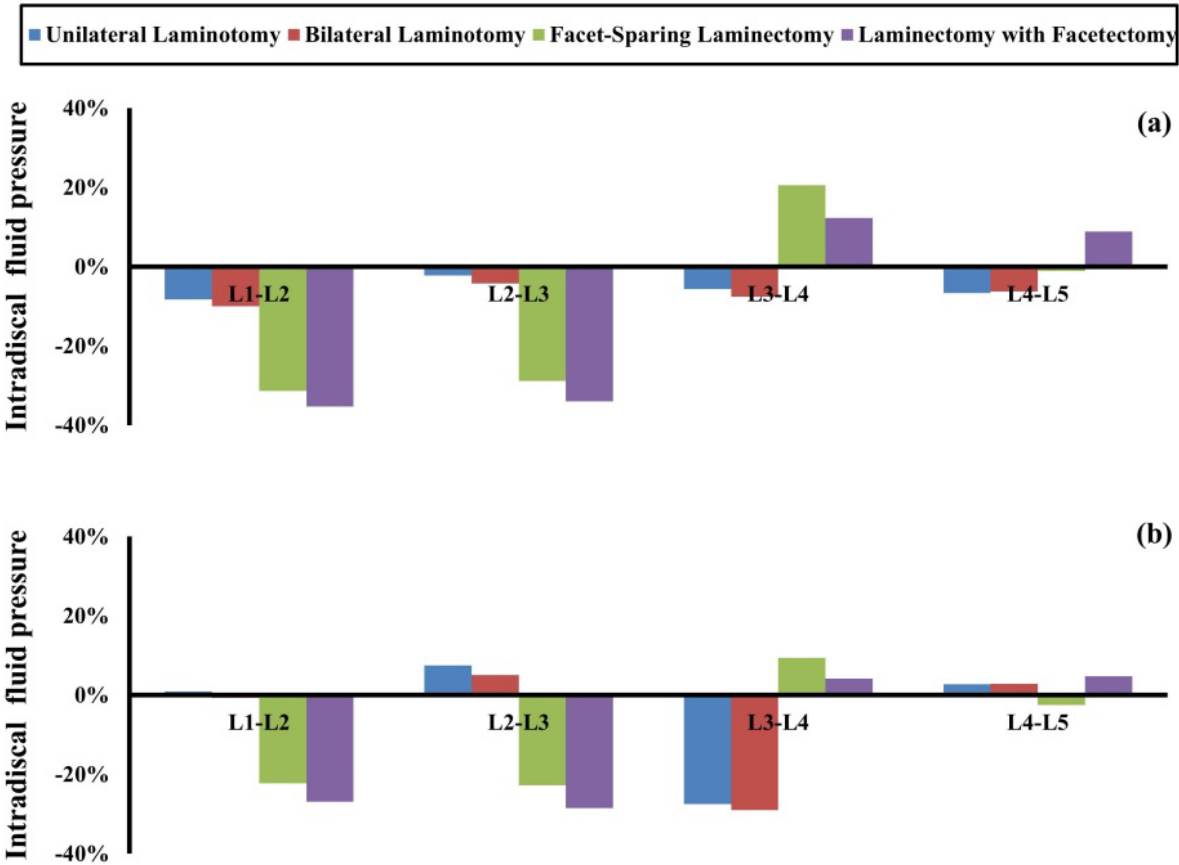

Figure 4: Post-operative changes in intradiscal peak pressure in spine segments: (a) intradiscal pressure in NP; (b) intradiscal pressure in AF. Data are reported in terms of percent change with respect to the 'intact' case.

biomechanical tests on a L1-L5 spinal column undergoing unilateral laminotomy, bilateral laminotomy, facet-sparing laminectomy, and laminectomy with facetectomy at L4-L5 to yield changes in kinematics, intradiscal pressure, and disc stress at all spine levels. Such metrics are especially relevant when investigating the etiology of ASD since altered range of motion of spine segments is believed to increase the risk of spinal instability, eventually leading to spondylolisthesis and LSS [3]. Besides, abnormal levels of fluid pressure or stress may suggest ongoing IVD degeneration, which also contributes to the development of stenosis [3,6,55-57].

The post-operative changes of spinal segments biomechanics were tested during flexion/extension. In agreement with both in 


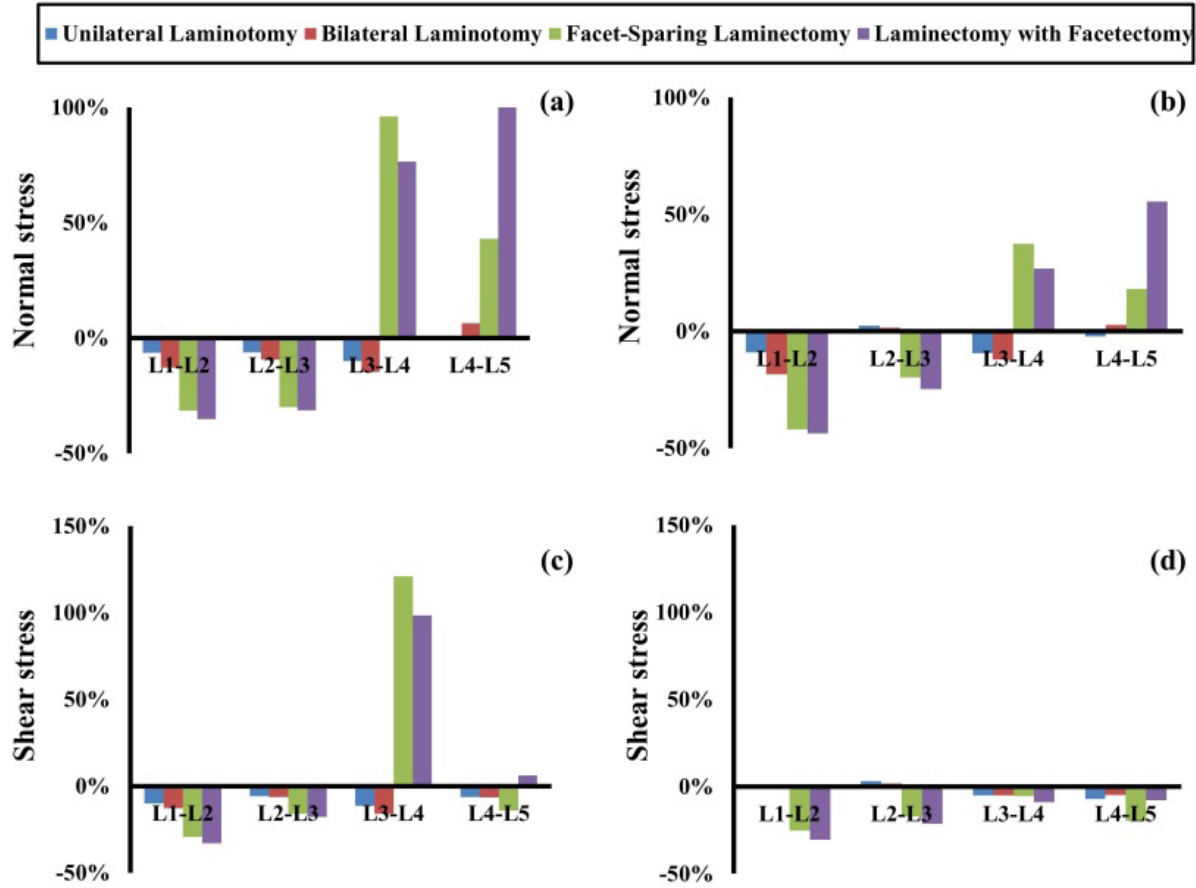

Figure 5: Post-operative changes in peak stress in spine segments: (a) normal stress in NP; (b) normal stress in AF; (c) shear stress in NP; (d) shear stress in AF. Data are reported in terms of percent change with respect to the 'intact' case.

vitro $[28,30,32]$ and numerical studies, $[34,39,40]$ no changes were observed during extension. The kinematic analysis carried out in this study shows that the largest increase in post-operative spine motion is attained at the operated level (L4-L5) and the immediate adjacent one (L3-L4) after laminectomies are performed (Figure 3). This is in agreement with previously reported in vitro [28-30] and numerical biomechanical analyses [34,35,40]. Moreover, these results are also consistent with clinical studies observing that laminotomy generates a lower level of instability when compared to laminectomy [20,25]. Post-laminotomy alterations of the kinematics at the levels L3-L4 and above are caused by the reduction of stiffness at L4-L5. In contrast, laminectomy of L4 also entails the removal of flavum, interspinous, and supraspinous ligaments, which connect this vertebra to both L3 and L5. These anatomic changes directly affect the stiffness of the adjacent segment L3-L4. It has been reported that over $60 \%$ of the flexion movement of the spine is taken up by the posterior ligaments. Among them, interspinous and supraspinous ligaments withstand the highest tensile force [58]. This would explain the fact that: (1) after laminotomy, alterations of L4-L5 kinematics were minor; (2) after laminectomy, the model predicted increase in motion during flexion and almost negligible changes during extension.

Changes in intradiscal pressure and stress can lead to altered metabolism within the disc, with potential long-term disc degeneration $[56,57,59,60]$. Minor changes are found after either unilateral or bilateral laminotomy $(<10 \%)$. In contrast, after laminectomy, variations of fluid pressure (up to 20\%) and stress (up to $120 \%$ ) occur in NP and anterior AF (Figures 4 and 5). However, these changes occurred at the operated level (L4-L5) and its immediate adjacent level L3-L4, while the other spine levels experienced reduction of both intradiscal pressure, and normal and shear stresses. These results are in agreement with an in vitro study on calf spine reporting that, after laminotomy, intradiscal pressure changes at the operated level did not statistically differ from those found in intact spine. In contrast, after laminectomy, significant pressure increase was found in the anterior portion of IVD [29]. Similar findings were also reported in a recent computational study showing intradiscal pressure increase up to $50 \%$ after laminectomy, and minor changes after laminotomy [34].

It has been historically reported that laminectomy with complete facetectomy induces excessive spinal instability, so that the more conservative facet-sparing laminectomy is typically performed to treat LSS [27,32,36-38]. This study confirms that, compared to facetsparing laminectomy, the complete facetectomy model yielded a larger increase in spine kinematics and, consequently, larger intradiscal pressure and stress at the operated level L4-L5. However, at the immediate adjacent level L3-L4, facet-sparing laminectomy caused the largest biomechanical alterations (Figures 4 and 5). Hence, according to model's predictions, the two laminectomy procedures are similarly detrimental for spine health, with laminectomy with facetectomy mostly altering the biomechanics of the operated level L4-L5, while facet-sparing laminectomy mainly affecting the adjacent segment L3-L4.

The advancements in minimally-invasive spine surgery have been promoted as a potential way to decrease the rate of ASD by diminishing paraspinal muscle damage and avoiding disruption of the midline structures that provide stability. While this topic has been recently studied in the context of spinal fusion surgery (open versus minimally invasive spinal fusion techniques), there is little known about the comparative rate of ASD in open versus minimally invasive spinal decompression surgery alone [61-64]. Multiple authors have reviewed outcomes of open versus minimally-invasive fusion transforaminal lumbar interbody fusion (TLIF) and have found a lower rate of ASD in the minimally-invasive groups, presumably due to less soft tissue dissection (e.g., less paraspinal muscle stripping) [63,64]. Radcliff and colleagues have reviewed the rate of ASD amongst various lumbar interventions and noted a rate of ASD of $2-3 \%$ per year [61]. The same authors performed a subsequent study of their own patients who underwent anterior lumbar interbody fusion (ALIF) and supplemental posterior instrumentation performed either open or percutaneously. 
The results of their study did not show a difference in rate of ASD between the two groups [62]. So while there is a strong theoretical advantage to minimally invasive spine surgical techniques, the clinical evidence that it reduces the rate of ASD is still somewhat equivocal. There is clearly a need for more comparative clinical studies reviewing this topic. Future directions for our present study will include biomechanical comparison using the same modeling techniques to determine the difference in adjacent level motion when various spinal stabilization/fusion techniques are applied, (i.e., posterior pedicle screw and rod instrumentation, interbody placement, etc).

Some limitations of this study must be noted. The model schematizes vertebrae as rigid bodies, so that the only deformable structures in the spine are the soft tissues (i.e., intervertebral discs, cartilage at facet joints, and ligaments). Such simplification may have affected the results of both kinematic and stress analyses hereby reported. However, the stiffness of the soft tissues in the spine is about two and four orders of magnitude lower than those of cancellous and cortical bone in vertebrae, respectively [65]. Accordingly, one would expect that, for the surgical procedures and loading conditions investigated in this study, spine strains mostly occur in the soft tissues. Also, spine ligaments were modeled as linear elastic elements, whose stiffness corresponded to the slope of the most linear portion of the force-deformation curve experimentally determined by Pintar and co-workers [51]. Ligaments linear behavior is considered the normal (physiologic) response of the tissue to routine external stimuli $[66,67]$. Accordingly, a linear behavior may be used as an initial approximation of ligament characteristics in computational models [51]. Moreover, another factor potentially affecting spine stability is the extent of paraspinal muscle damage associated to the specific surgical procedure performed. However, the contribution of muscles to spine biomechanical stability was not accounted for in the present finite element model, and its inclusion will be addressed in our future studies. Also, laminotomy and laminectomy are characterized by a similar degree of paraspinal muscle dissection. Finally, the computational model used in this study was validated through kinematic data from an in vitro study only reporting spine kinematics during flexion/extension [28]. Accordingly, the results reported in this study are only relevant for the case of flexion/extension spine motion, since other physiologically relevant movements (e.g., axial rotation, lateral bending, etc.) were not studied, and will be addressed in the future upon further model validation.

For the loading conditions investigated in this analysis, our results suggest that laminotomy, whether unilateral or bilateral, represents a superior technique in terms of potential risk reduction for developing either spine instability or mechanically-accelerated disc degeneration in the adjacent segment. However, additional tests, under different and more complex physiologically relevant loading conditions, should be performed in order to confirm our findings. Moreover, it is recognized that surgical decision-making must take into account many other factors, among which the severity of the stenosis. While laminotomy has been recommended for cases of moderate or unilateral stenosis, and it might not allow for adequate decompression of severe central or bilateral stenosis [25] in which case laminectomy may represent a better surgical solution despite the increase in instability shown in our study.

\section{Acknowledgments}

Study supported by funds donated to Biomechanics Research Group of the University of Miami. The authors have no conflict of interest to disclose.

\section{References}

1. Sasaki K (1995) Magnetic resonance imaging findings of the lumbar root pathway in patients over 50 years old. Eur Spine J 4: 71-76.
2. Englund J (2007) Lumbar spinal stenosis. Curr Sports Med Rep 6: 50-55.

3. Arbit E, Pannullo S (2001) Lumbar stenosis: a clinical review. Clin Orthop Relat Res 137-143.

4. Katz JN, Harris MB (2008) Clinical practice. Lumbar spinal stenosis. N Engl J Med 358: 818-825.

5. Hall S, Bartleson JD, Onofrio BM (1985) Lumbar spinal stenosis: clinical features, diagnostic procedures, and results of surgical treatment in 68 patients. Annals of Internal Medicine 103: 271-275.

6. Yong-Hing K, Kirkaldy-Willis WH (1983) The pathophysiology of degenerative disease of the lumbar spine. Orthop Clin North Am 14: 491-504.

7. Benz RJ, Garfin SR (2001) Current techniques of decompression of the lumbar spine. Clin Orthop Relat Res 75-81.

8. Turner JA, Ersek M, Herron L, Deyo R (1992) Surgery for lumbar spina stenosis. Attempted meta-analysis of the literature. Spine (Phila Pa 1976) 17 $1-8$.

9. Lee CK (1988) Accelerated degeneration of the segment adjacent to a lumbar fusion. Spine (Phila Pa 1976) 13: 375-377.

10. Aota Y, Kumano K, Hirabayashi S (1995) Postfusion instability at the adjacent segments after rigid pedicle screw flxation for degenerative lumbar spinal disorders. Journal of Spinal Disorders 8: 464-473.

11. Rahm MD, Hall BB (1996) Adjacent-segment degeneration after lumbar fusion with instrumentation: a retrospective study. J Spinal Disord 9: 392-400.

12. Throckmorton TW, Hilibrand AS, Mencio GA (2003) The impact of adjacent level disc degeneration on health status outcomes following lumbar fusion. Spine 28: 2546-2550.

13. Etebar S, Cahill DW (1999) Risk factors for adjacent-segment failure following lumbar fixation with rigid instrumentation for degenerative instability. J Neurosurg 90: 163-169.

14. Lai PL, Chen LH, Niu CC, Fu TS, Chen WJ (2004) Relation between laminectomy and development of adjacent segment instability after lumbar fusion with pedicle fixation. Spine (Phila Pa 1976) 29: 2527-2532.

15. Ghiselli G, Wang JC, Bhatia NN, Hsu WK, Dawson EG (2004) Adjacent segment degeneration in the lumbar spine. J Bone Joint Surg Am 86-86A 1497-503.

16. Mannion AF, Leivseth G, Brox J-I (2014) ISSLS Prize Winner: Long-term followup suggests spinal fusion is associated with increased adjacent segment disc degeneration but without influence on clinical outcome. Spine 39: 1373-1383.

17. Ekman P, Möller H, Shalabi A, Yu YX, Hedlund R (2009) A prospective randomised study on the long-term effect of lumbar fusion on adjacent disc degeneration. Eur Spine J 18: 1175-1186.

18. Park P, Garton HJ, Gala VC, Hoff JT, McGillicuddy JE (2004) Adjacent segment disease after lumbar or lumbosacral fusion: review of the literature. Spine (Phila Pa 1976) 29: 1938-1944.

19. Cardoso MJ, Dmitriev AE, Helgeson M, Lehman RA, Kuklo TR, et al. (2008) Does superior-segment facet violation or laminectomy destabilize the adjacent level in lumbar transpedicular fixation? An in vitro human cadaveric assessment. Spine (Phila Pa 1976) 33: 2868-2873.

20. Thome C, Zevgaridis D, Leheta O (2005) Outcome after less-invasive decompression of lumbar spinal stenosis: a randomized comparison of unilateral laminotomy, bilateral laminotomy, and laminectomy. Journal of Neurosurgery: Spine 3: 129-141.

21. Tsai RY, Yang RS, Bray RS Jr (1998) Microscopic laminotomies for degenerative lumbar spinal stenosis. J Spinal Disord 11: 389-394.

22. Aryanpur J, Ducker T (1990) Multilevel lumbar laminotomies: an alternative to laminectomy in the treatment of lumbar stenosis. Neurosurgery 26: 429-432.

23. Hong SW, Choi KY, Ahn Y, Baek OK, Wang JC, et al. (2011) A comparison of unilateral and bilateral laminotomies for decompression of L4-L5 spinal stenosis. Spine (Phila Pa 1976) 36: E172-178.

24. Kim SW, Ju Cl, Kim C (2007) Minimally invasive lumbar spinal decompression: A comparative study between bilateral laminotomy and unilateral laminotomy for bilateral decompression. Journal of Korean Neurosurgical Society 42: 195-199.

25. Postacchini F, Cinotti G, Perugia D (1993) The surgical treatment of centra lumbar stenosis. Multiple laminotomy compared with total laminectomy. Bone and Joint Surgery, British 75: 386-392. 
Citation: Travascio F, Asfour S, Gjolaj J, Latta LL, Elmasry S, Eismont F (2015) Implications of Decompressive Surgical Procedures for Lumbar Spine Stenosis on the Biomechanics of the Adjacent Segment: A Finite Element Analysis. J Spine 4: 220. doi:10.4172/21657939.1000220

Page 7 of 7

26. Fu YS, Zeng BF, Xu JG (2008) Long-term outcomes of two different decompressive techniques for lumbar spinal stenosis. Spine (Phila Pa 1976) 33: $514-518$

27. Natelson SE (1986) The injudicious laminectomy. Spine (Phila Pa 1976) 11 966-969.

28. Lee MJ, Bransford RJ, Bellabarba C, Chapman JR, Cohen AM, et al. (2010) The effect of bilateral laminotomy versus laminectomy on the motion and stiffness of the human lumbar spine: a biomechanical comparison. Spine (Phila Pa 1976) 35: 1789-1793.

29. Rao RD, Wang M, Singhal P, McGrady LM, Rao S (2002) Intradiscal pressure and kinematic behavior of lumbar spine after bilateral laminotomy and laminectomy. Spine J 2: 320-326.

30. Tai CL, Hsieh PH, Chen WP (2008) Biomechanical comparison of lumbar spine instability between laminectomy and bilateral laminotomy for spinal stenosis syndrome - an experimental study in porcine model. BMC musculoskeletal disorders 9: 84 .

31. Quint U, Wilke HJ, Loer F (1998) Laminectomy and functional impairment of the lumbar spine: the importance of muscle forces in flexible and rigid instrumented stabilization - a biomechanical study in vitro. European Spine Journal 7: 229-238.

32. Abumi K, Panjabi MM, Kramer KM, Duranceau J, Oxland T, et al. (1990) Biomechanical evaluation of lumbar spinal stability after graded facetectomies. Spine (Phila Pa 1976) 15: 1142-1147.

33. Lu WW, Luk KD, Ruan DK, Fei ZQ, Leong JC (1999) Stability of the whole lumbar spine after multilevel fenestration and discectomy. Spine (Phila Pa 1976) 24: 1277-1282.

34. Elgafy H, Goel VK, Terai T (2009) Midline sparing bilateral laminotomy prevents disc collapse as compared to traditional laminectomy - A biomechanical finite element analysis. The Spine Journal 9: 134S-135S

35. Bresnahan L, Ogden AT, Natarajan RN, Fessler RG (2009) A biomechanical evaluation of graded posterior element removal for treatment of lumbar stenosis: comparison of a minimally invasive approach with two standard laminectomy techniques. Spine (Phila Pa 1976) 34: 17-23.

36. Lee KK, Teo EC (2004) Effects of laminectomy and facetectomy on the stability of the lumbar motion segment. Med Eng Phys 26: 183-192.

37. Lee KK, Teo EC, Qiu TX, Yang K (2004) Effect of facetectomy on lumbar spina stability under sagittal plane loadings. Spine (Phila Pa 1976) 29: 1624-1631.

38. Natarajan RN, Andersson GBJ, Patwardhan AG (1999) Study on effect of graded facetectomy on change in lumbar motion segment torsional flexibility using three-dimensional continuum contact representation for facet joints. Journal of Biomechanical Engineering 121: 215-221.

39. Zander T, Rohlmann A, Klöckner C, Bergmann G (2003) Influence of graded facetectomy and laminectomy on spinal biomechanics. Eur Spine J 12: 427-434.

40. Sairyo K, Goel VK, Masuda A (2005) Biomechanical rationale of endoscopic decompression for lumbar spondylolysis as an effective minimally invasive procedure-a study based on the finite element analysis. Minimally Invasive Neurosurgery 48: 119-122.

41. Bowen RM (1980) Incompressible porous media models by use of the theory of mixtures. International Journal of Engineering Science 18: 1129-1148.

42. Mow VC, Kuei SC, Lai WM, Armstrong CG (1980) Biphasic creep and stress relaxation of articular cartilage in compression? Theory and experiments. J Biomech Eng 102: 73-84.

43. Shirazi-AdA, Ahmed AM, Shrivastava SC (1986) Mechanical response of a lumbar motion segment in axial torque alone and combined with compression. Spine (Phila Pa 1976) 11: 914-927.

44. Zander T, Rohlmann A, Calisse J, Bergmann G (2001) Estimation of muscle forces in the lumbar spine during upper-body inclination. Clin Biomech (Bristol, Avon) 16 Suppl 1: S73-80.

45. Schmidt H, Heuer F, Simon U, et al. (2006). Application of a new calibration method for a three-dimensional finite element model of a human lumbar annulus fibrosus. Clinical Biomechanics 21: 337-344.

46. Natarajan RN, Andersson GB (1999) The influence of lumbar disc height and cross-sectional area on the mechanical response of the disc to physiologic loading. Spine (Phila Pa 1976) 24: 1873-1881.

47. Antoniou J, Steffen T, Nelson F, Winterbottom N, Hollander AP, et al. (1996) The human lumbar intervertebral disc: evidence for changes in the biosynthesis and denaturation of the extracellular matrix with growth, maturation, ageing, and degeneration. J Clin Invest 98: 996-1003.
48. latridis JC, Setton LA, Foster RJ, Rawlins BA, Weidenbaum M, et al. (1998) Degeneration affects the anisotropic and nonlinear behaviors of human anulus fibrosus in compression. J Biomech 31: 535-544.

49. Perie D, Korda D, latridis JC (2005) Confined compression experiments on bovine nucleus pulposus and annulus fibrosus: sensitivity of the experiment in the determination of compressive modulus and hydraulic permeability. Journal of Biomechanics 38: 2164-2171.

50. Schmidt H, Galbusera F, Rohlmann A, Zander T, Wilke HJ (2012) Effect of multilevel lumbar disc arthroplasty on spine kinematics and facet joint loads in flexion and extension: a finite element analysis. Eur Spine J 21 Suppl 5 : S663-674.

51. Pintar FA, Yoganandan N, Myers T, Elhagediab A, Sances A Jr (1992) Biomechanical properties of human lumbar spine ligaments. J Biomech 25 1351-1356.

52. Ateshian GA, Maas S, Weiss JA (2012) Solute transport across a contact interface in deformable porous media. J Biomech 45: 1023-1027.

53. Maas SA, Ellis BJ, Ateshian GA, Weiss JA (2012) FEBio: finite elements for biomechanics. J Biomech Eng 134: 011005.

54. Shirazi-Adl A, Parnianpour M (2000) Load-bearing and stress analysis of the human spine under a novel wrapping compression loading. Clin Biomech (Bristol, Avon) 15: 718-725.

55. Panjabi MM (2007) Hybrid multidirectional test method to evaluate spinal adjacent-level effects. Clin Biomech (Bristol, Avon) 22: 257-265.

56. Stokes IA, latridis JC (2004) Mechanical conditions that accelerate intervertebral disc degeneration: overload versus immobilization. Spine (Phila Pa 1976) 29 2724-2732.

57. latridis JC, MacLean JJ, Roughley PJ, Alini M (2006) Effects of mechanica loading on intervertebral disc metabolism in vivo. J Bone Joint Surg Am 88 Suppl 2: 41-46.

58. Goel VK, Fromknecht SJ, Nishiyama K, Weinstein J, Liu YK (1985) The role of lumbar spinal elements in flexion. Spine (Phila Pa 1976) 10: 516-523.

59. Holm S, Nachemson A (1983) Variations in the nutrition of the canine intervertebral disc induced by motion. Spine (Phila Pa 1976) 8: 866-874.

60. Hutton WC, Toribatake Y, Elmer WA, Ganey TM, Tomita K, et al. (1998) The effect of compressive force applied to the intervertebral disc in vivo. A study of proteoglycans and collagen. Spine (Phila Pa 1976) 23: 2524-2537.

61. Radcliff KE, Kepler CK, Jakoi A, Sidhu GS, Rihn J, et al. (2013) Adjacent segment disease in the lumbar spine following different treatment interventions. Spine J 13: 1339-1349.

62. Radcliff KE, Kepler CK, Maaieh M, Anderson DG, Rinn J, et al. (2014) What is the rate of lumbar adjacent segment disease after percutaneous versus open fusion? Orthop Surg 6: 118-120.

63. Seng C, Siddiqui MA, Wong KP, Zhang K, Yeo W, et al. (2013) Five-year outcomes of minimally invasive versus open transforaminal lumbar interbody fusion: a matched-pair comparison study. Spine (Phila Pa 1976) 38: 2049-2055.

64. Yee TJ, Terman SW, La Marca F, Park P (2014) Comparison of adjacent segment disease after minimally invasive or open transforaminal lumbar interbody fusion. J Clin Neurosci 21: 1796-1801.

65. Shirazi-Adl SA, Shrivastava SC, Ahmed AM (1984) Stress analysis of the lumbar disc-body unit in compression. A three-dimensional nonlinear finite element study. Spine (Phila Pa 1976) 9: 120-134.

66. White AA, Panjabi MM (1990) Clinical biomechanics of the spine. Philadelphia PA: Lippincott;

67. Yoganandan N, Maiman DJ, Pintar F, Ray G, Myklebust JB, et al. (1988) Microtrauma in the lumbar spine: a cause of low back pain. Neurosurgery 23 162-168. 